\title{
A facile energy and water-conserving process for cotton dyeing
}

\author{
Rachana S. Harane $\cdot$ Neha R. Mehra $\cdot$ \\ Priti B. Tayade $\cdot$ Ravindra V. Adivarekar
}

Received: 30 October 2013/Accepted: 13 February 2014/Published online: 25 April 2014

(C) The Author(s) 2014. This article is published with open access at Springerlink.com

\begin{abstract}
Nowadays, all research efforts in the field of wet processing of textiles are directed towards shortening and simplification of the processing sequence. To minimise water and energy consumption, it has become necessary to combine several textile processing stages to reduce the number of operations or shorten the process time. An attempt was made to combine the pre-treatment and dyeing processes with optimal quantities of textile auxiliaries in single bath. In this process, individual stages of pre-treatment like desizing, scouring and bleaching followed by dyeing using direct dyes were carried out in a single bath without the usual intermediate washings. This process was carried out without replacing the liquor bath until the end of dyeing. An attempt was also made to dye a woven fabric at different stages, viz., grey, desizing and scouring. These efforts were made to conserve water and energy required for that particular pre-treatment process. The depth of dyeing and the colour fastness properties of all these dyed fabrics were then compared with a bleached fabric which was dyed with conventional method. The properties were at par with the conventional method. Moreover, the combined
\end{abstract}

\footnotetext{
R. S. Harane - N. R. Mehra - P. B. Tayade .

R. V. Adivarekar ( $\square)$

Department of Fibres and Textile Processing Technology,

Institute of Chemical Technology (ICT), Matunga,

Mumbai 400019, Maharashtra, India

e-mail: ict.ravindra@gmail.com;

rv.adivarekar@ictmumbai.edu.in

R. S. Harane

e-mail: rachana.harane@gmail.com

N. R. Mehra

e-mail: nehaskhurana@gmail.com

P. B. Tayade

e-mail: pritibtayade@gmail.com
}

process saved $83.1 \%$ water, $88.6 \%$ energy (thermal) and $79.3 \%$ time than the conventional processes. Thus, the process has been shown to be ecological, economical and energy conserving.

Keywords Pre-treatment - Dyeing - Direct dyes . Single bath · Depth of dyeing · Colour fastness . Energy conserving
Abbreviations
AATCC American Association of Textile Chemists and Colorists
$\mathrm{d} E \quad$ Colour difference between reference
and sample fabric
ISO International Organisation for Standardisation
K/S Kubelka-Munk equation
MLR Material to liquor ratio
RFD Ready for dyeing fabric

\section{Introduction}

The conventional three-stage desizing, scouring and bleaching operations are exceptionally intensive in water, energy and chemicals which ultimately influence the process cost. At the same time, limited availability of water is also a challenge. The water requirement varies from mill to mill depending on the process sequence they follow. The quantity of water required for textile processing depends on the textile process, fabric produced, the equipment type and dyestuffs.

Conventional preparation of cotton-based textiles usually involves desizing of the starch (size) applied to the yarn during weaving, scouring of the material to remove the natural hydrophobic impurities such as fats and waxes, followed by a bleaching process to impart whiteness by 
Table 1 Water required for cotton textile wet processing [4]

\begin{tabular}{ll}
\hline Processes & Water requirements in $\mathrm{L} / 1,000 \mathrm{~kg}$ of products \\
\hline Desizing & $2,500-21,000$ \\
Scouring & $20,000-45,000$ \\
Bleaching & $2,500-25,000$ \\
Dyeing & $10,000-300,000$ \\
Printing & $8,000-16,000$ \\
\hline
\end{tabular}

destroying the natural colouring matter [1-3]. The water usage required for different wet-processing stages in a typical cotton textile mill is given in Table 1 [4].

From Table 1, it is clear that the pre-treatment process, i.e. desizing, scouring and bleaching, involves more water usage. Also, about 55 to $60 \%$ energy consumed in the textile industry is used in various pre-treatment stages [5]. The high consumption of water and energy for textile wetprocessing sector emphasises the urge for improvement of process, i.e. to adopt cost effective practices to reduce the use of scarce resources like water and energy. Hence, the logical approach to combine desizing, scouring and bleaching operations to save energy and water was put forward by many researchers [6-10].

Various researchers have also worked on combining pre-treatment and dyeing processes using various enzymes. Quardt and Kuhl [11] have attempted to use enzymes from the beginning to the end of the finishing processes of textile substrates. Hardt et al. [12] carried out single-bath bleaching and dyeing processes with ecologically optimal textile auxiliaries. These are processes in which individual stages of treatment, viz., acid demineralisation, alkaline scouring, hydrogen peroxide bleaching and the elimination of residual peroxide with subsequent reactive dyeing occur without the normal intermediate washings. Losonczi et al. [13] studied the conventional and bio-preparation scouring processes of cotton fabrics and also studied the bleaching and dyeing with reactive dyes of such pre-treated fabrics. Kokol and Golob [14] performed biopreparation of raw cotton using enzymes and also carried out reactive dyeing in the same bath. Oner and Sahinbaskan [15] carried out all of the stages viz., desizing, scouring, bleaching and dyeing in a single bath without replacing the process water until the end of the dyeing. They named the process 'Rapid Enzymatic Single-bath Treatment' (REST), since it was completed almost in half of the conventional dyeing time.

In this work, we take further steps to challenge the conventional preparatory and the dyeing processes. The aim of the work was to ensure efficient reduction in water consumption in the cotton wet-processing sector. There is a tendency to use more amount of water than required while removing the residual chemicals during rinsing [16]. To fulfil the objective, an unprocessed grey fabric was subjected to combined pre- treatment and dyeing process which was carried out using all the conventional chemicals in the same bath. Successful attempt were also made to dye fabrics at grey stage, desized stage and scoured stage. This was carried out to check the dyeing efficiency of a grey fabric after various steps of pretreatment. Through this attempt, we tried to question the practical need of pre-treatment processes given to a grey fabric. These processes impart hydrophilicity to the otherwise hydrophobic grey fabric. We were able to dye a grey unprocessed fabric with acceptable and almost comparable properties as of a RFD fabric in our work. Though the absorbency time of grey dyed fabric is more, one can utilise these fabrics depending on their end use, e.g. upholstery fabric, technical textiles, etc. where a good absorbency is not of utmost importance. We also should take into notice that this can tremendously save water, chemicals and energy required for processing a fabric for making it ready for dyeing.

Thus, efforts were made towards not only reducing the water intake and minimise the intermediate washings but also to minimise the intake of chemicals wherever possible to make existing process, 'more sustainable' and 'environment friendly'.

\section{Materials and methods}

\section{Materials}

A $100 \%$ grey cotton fabric used for experiments was procured from Tata mills, Mumbai, with a plain weave having a yarn count of 40 (The count of the cotton yarn is equal to the number of 840-yard skeins of cotton required to weigh 1 pound) and with a weight of $85 \mathrm{~g} / \mathrm{m}^{2}$. The size content on the grey fabric was $12 \%$.

The chemicals used were hydrochloric acid $(\mathrm{HCl})$, wetting agent (Turkey Red Oil), sodium hydroxide $(\mathrm{NaOH})$, sodium carbonate $\left(\mathrm{Na}_{2} \mathrm{CO}_{3}\right)$, hydrogen peroxide $\left(\mathrm{H}_{2} \mathrm{O}_{2}\right)$, sodium silicate (peroxide stabiliser), Glauber's salt and glacial acetic acid. All chemicals were supplied by S.D. Fine chemicals and were of AR grade. Saradye FN (dye fixing agent) was procured from Sarex Chemicals Ltd.

The direct dyes namely, CB Direct Red 5B, CB Direct Blue GLL, CB Direct Black FR, CB Direct Olive Green BL, CB Direct Yellow 5GLL and CB Direct Turquoise Blue BRLE $150 \%$, procured from Colorband India Pvt. Ltd were used for the study.

Experimental methods

\section{Conventional methods}

Desizing process Initially weighed grey cotton woven fabric was taken and treated with $2 \% \mathrm{HCl}$ and $1 \%$ wetting 
agent at a temperature of $50-60{ }^{\circ} \mathrm{C}$ for $2 \mathrm{~h}$, excluding the time required for heating, which is $15 \mathrm{~min}$ at a heating rate $2{ }^{\circ} \mathrm{C} / \mathrm{min}$, with a material to liquor ratio (MLR) of $1: 30$ in a standing bath. After this, the sample was given a cold wash for $5 \mathrm{~min}$ followed by hot wash at $60{ }^{\circ} \mathrm{C}$ for $10 \mathrm{~min}$. The fabric was given a neutralisation treatment with dilute alkali at $30{ }^{\circ} \mathrm{C}$ for $10 \mathrm{~min}$ and dried. Weight loss was measured. The fabric sample was also given Tegewa rating to ensure proper size removal.

Scouring process Initially weighed desized cotton woven fabric was treated with $10 \mathrm{~g} / \mathrm{L} \mathrm{NaOH}, 5 \mathrm{~g} / \mathrm{L} \mathrm{Na} \mathrm{CO}_{3}$ and $2 \mathrm{~g} / \mathrm{L}$ wetting agent at boil for 2-3 h, excluding the time required for heating, which is $35 \mathrm{~min}$ at a heating rate $2{ }^{\circ} \mathrm{C} / \mathrm{min}$, at MLR of 1:30. After this, the sample was given cold wash for $5 \mathrm{~min}$ followed by a hot wash at $60{ }^{\circ} \mathrm{C}$ for $10 \mathrm{~min}$ and dried and weight loss and absorbency was calculated.

Bleaching process Initially weighed desized and scoured cotton woven fabric was taken and treated with $5 \mathrm{~g} / \mathrm{L} \mathrm{H}_{2} \mathrm{O}_{2}$, 2-5 g/L Sodium silicate and $2-5 \mathrm{~g} / \mathrm{L} \mathrm{Na}_{2} \mathrm{CO}_{3}$ at a temperature of $80-85^{\circ} \mathrm{C}$ for $1 \mathrm{~h}$, excluding the time required for heating, which is $27 \mathrm{~min}$ at a heating rate $5{ }^{\circ} \mathrm{C} / \mathrm{min}$ at an MLR of 1:30. After this, the sample was given cold wash for $5 \mathrm{~min}$ followed by a hot wash at $60{ }^{\circ} \mathrm{C}$ for $10 \mathrm{~min}$ and was neutralised by acetic acid at $30{ }^{\circ} \mathrm{C}$ for $10 \mathrm{~min}$. The fabric was dried and measured for Whiteness Index to ensure complete decolourisation of coloured impurities.

Direct dyeing of cotton fabric A dye bath was prepared at room temperature by adding bleached cotton fabric and required amount of Glauber's salt. Sodium carbonate was added only for black shades to get a $\mathrm{pH}$ of 7-8. Then, required amount of dye was pipetted out from stock solution $(1 \%)$ into dye bath. The temperature of the dyebath was raised to $100{ }^{\circ} \mathrm{C}$ by keeping $1.5^{\circ} \mathrm{C} / \mathrm{min}$ temperature gradient and the process was carried out for $1 \mathrm{~h}$ in rota dyer at an MLR of 1:20. After this, the bath was drained and the fabric was rinsed thoroughly with cold water for $5 \mathrm{~min}$ followed by treatment with $1 \%$ dye fixing agent at $60{ }^{\circ} \mathrm{C}$ for $30 \mathrm{~min}$. Then, the fabric was rinsed and dried.

\section{Modified method}

In the modified method, pre-treatment and dyeing was carried out in a single bath. A dye bath was prepared at room temperature using $1 \mathrm{~g} / \mathrm{L}$ wetting agent, $5 \mathrm{~g} / \mathrm{L} \mathrm{NaOH}$, $3 \mathrm{~mL} / \mathrm{L} \mathrm{H}_{2} \mathrm{O}_{2}, 50 \%$ w/v (i.e. $50 \mathrm{~g}$ of hydrogen peroxide was weighed and was diluted up to $100 \mathrm{ml}$ of water.) $1 \mathrm{~g} / \mathrm{L}$ sodium silicate (peroxide stabilizer). The required amount of direct dye was also added in the same bath along with $15 \mathrm{~g} / \mathrm{L}$ Glauber's salt. Sodium carbonate was added only for black shades to get a $\mathrm{pH}$ of 7-8. To this bath, grey woven fabric was added. Temperature was raised to $100{ }^{\circ} \mathrm{C}$ by keeping $1.5^{\circ} \mathrm{C} / \mathrm{min}$ temperature gradient and processing was carried out for $1 \mathrm{~h}$ in rota dyer at an MLR of 1:20. The fabric was then rinsed thoroughly with cold water for 5 min and was treated with $1 \%$ dye fixing agent for $30 \mathrm{~min}$ at $60{ }^{\circ} \mathrm{C}$. Fabric was again given cold wash for $5 \mathrm{~min}$ and air dried.

Testing and analysis

\section{Testing of desized fabric}

Principle With starch sizes, the Iodine reagent (Iodine + Potassium Iodide) produces a coloured complex of intense violet blue colour. The coloured complex formed is a two-dimensional complex, where iodine, the linear chain, is included in a two-dimensional structure of the starch. This test is practical because it directly indicates either the presence of the starch by a characteristic deep blue colouration or the absence of the starch by a yellowish orange or no colouration on the fabric.

Preparation of the iodine solution For preparation of iodine solution, $10 \mathrm{~g}$ of potassium iodide was dissolved in $100 \mathrm{~mL}$ of water and $0.65 \mathrm{~g}$ of iodine was added into it. This solution was stirred for complete dissolution. To the above solution, $800 \mathrm{~mL}$ water was added and further ethanol was added to make up the volume up to $1 \mathrm{~L}$.

Application of the iodine solution Grey fabric sample was dipped in the above-mentioned iodine solution for $1 \mathrm{~min}$, was then rinsed with cold water and dabbed with filter paper. Then, this fabric was compared immediately with violet scale (Tegewa Scale) and accordingly rating was given. The scale has 1-9 rating. Rating 1 is poor, and a 9 rating is the best which indicates complete removal of size from the fabric. Commercially acceptable rating is 6-7.

\section{Testing of scoured fabric}

Absorbency test was performed using AATCC Test Method 79-1995, details of this method are given in [17].

\section{Testing of bleached fabric}

The bleached fabrics were evaluated for whiteness index using computer colour matching system (SpectraScan $5100+$ ) supplied by Premier Colorscan Instruments Pvt. Ltd. Bleached fabric was evaluated for whiteness index using AATCC test method 110-2005 [18]. An average of two readings taken at two different positions of samples was used to calculate the indices. 
Colour depth (in terms of K/S value and colour strength) and colour difference (in terms of $L, a$ and $b$ values)

Dyed samples were evaluated by determining K/S values as well as colour strength using computer colour matching system (SpectraScan 5100+) supplied by Premier Colorscan Instruments Pvt. Ltd. An average of two readings which was taken at two different positions of samples was used to calculate the Kubelka-Munk, i.e. K/S function which is given by,

$K / S=(1-R)^{2} / 2 R$

where, $R$ the reflectance at complete opacity

$K$ the absorption coefficient

$S$ the scattering coefficient

The colour difference $(\mathrm{d} E)$ can be visualised as the distance between the standard or reference and the sample points plotted in the $L a b$ colour space. $L$ values have a range of 0-100, 100 indicates lightness or white and 0 indicates darkness or black. Negative values of ' $a$ ' indicate green while positive values indicate red, whereas negative values of ' $b$ ' indicate blue and positive values indicate yellow. The $L a b$ system adopted from the CIE in 1976 is the most widely used system today [19].

$\mathrm{D} E=\left(\mathrm{D} L^{2}+\mathrm{D} a^{2+} \mathrm{D} b^{2}\right)^{1 / 2}$

where $\mathrm{D} L=L$ (sample) $-L$ (standard)

$\mathrm{D} a=a$ (sample $)-a$ (standard $)$

$\mathrm{D} b=b$ (sample $)-b$ (standard $)$

From the CIELAB coordinates, one can compute $C$ (chroma) and $h$ (hue). The Chroma or saturation $(C)$ is the distance between achromatic point and colour is calculated from ' $a$ ' \& ' $b$ ' using following equation;

$C=\left(a^{2}+b^{2}\right)^{1 / 2}$

The point $a=0$ and $b=0$ lies at the centre of the chromaticity diagram. Lower is the value of ' $a$ ' and ' $b$ ', higher is the achromaticity and lower is the purity. On the other hand, higher the values of ' $a$ ' and ' $b$ ' (ignore the negative signs), purer or more saturated or brighter is the colour.

$h=\tan ^{-1}(b / a)$ in degrees

Positive values of chroma (or saturation) indicate more saturated colour (i.e. brighter) and negative values indicate less saturated colour (i.e. duller). Hue is an angle and can also be termed as purity of colour [19].

\section{Washing fastness evaluation}

Washing fastness of dyed fabrics was done using ISO 105-C03 [20]. In this method, the specimen is sandwiched between a wool fabric and a bleached fabric and is stitched.
Then, it is placed in the container along with $5 \mathrm{~g} / \mathrm{L}$ soap solution and $2 \mathrm{~g} / \mathrm{L}$ sodium carbonate with an MLR of 1:50. It was run at a temperature of $60 \pm 2{ }^{\circ} \mathrm{C}$ for $30 \mathrm{~min}$. Then, the sample was removed, rinsed twice under tap water for $10 \mathrm{~min}$ and squeezed. Then, it was air dried and the required testing was carried out, i.e. change in the colour of the dyed specimen, staining on cotton fabric and staining of wool fabric.

\section{Light fastness evaluation}

The light fastness of the dyed samples was tested on Q-sun light fastness tester and the fastness was graded for the colour change when the samples were partially exposed to the Xenon lamp for $8 \mathrm{~h}$. The method adopted is ISO 105-B02 (which is similar to AATCC 16) [21].

\section{Rubbing fastness evaluation}

Rubbing fastness of the dyed samples was determined using automatic Crockmeter. The method adopted is from ISO 105 X12 evaluation procedure [22]. Both dry rubbing and wet rubbing of the dyed fabric were assessed. Suitable testing device for determining the colour fastness to rubbing consists of a reciprocating straight line rubbing motion and a rubbing finger. The rubbing finger shall exert a downward force of $9 \pm 0.2 \mathrm{~N}$ moving to and fro 20 times, 10 times in each direction in a straight line along a path of $10 \pm 3 \mathrm{~cm}$ track. A bleached white fabric is attached to the rubbing finger and is rubbed against the dyed sample. While assessing wet rubbing fastness, the fabric is moistened with water and then rubbed. The staining of the cotton rubbing cloths is assessed with the grey scale for staining.

\section{Results and discussions}

Desizing was carried out using conventional method as described in the experimental methods, weight loss and Tegewa rating was measured to check removal of size. The weight loss after desizing process was $10.5 \%$ and a Tegewa rating of 6 was observed which was due to the removal of large quantity of size present on the grey fabric.

Conventional dyeing was carried out using direct dyes on a bleached fabric, i.e. RFD (Ready for Dyeing) fabric. Also, grey, desized and desized-scoured fabrics were dyed using direct dyes by same method as of the conventional dyeing. One bath pre-treatment and dyeing was also carried out. The results in terms of $\mathrm{dE}, K / S$, relative strength, $L, a$, $b, C, h$ values of all the dyed fabrics are given in the Table 2. A graphical representation of relative strength (\%) of all the dyed fabric samples is given in Fig. 1. 
Table 2 Dyeing properties of plain woven cotton fabric with direct dyes

\begin{tabular}{|c|c|c|c|c|c|c|c|c|c|}
\hline Dyes/Samples & $\mathrm{d} E$ & & $K / S$ & $\begin{array}{l}\text { Relative } \\
\text { strength (\%) }\end{array}$ & $L$ & $a$ & $b$ & $C$ & $h$ \\
\hline \multirow[t]{5}{*}{ Red 5B } & $\mathrm{A}$ & - & 5.44 & 100 & 49.277 & 46.568 & 9.557 & 47.539 & 11.593 \\
\hline & $\mathrm{B}$ & 0.70 & 8.57 & 157.46 & 49.686 & 46.473 & 10.128 & 47.564 & 12.289 \\
\hline & $\mathrm{C}$ & 0.65 & 9.60 & 176.41 & 49.327 & 45.996 & 9.88 & 47.045 & 12.118 \\
\hline & $\mathrm{D}$ & 0.63 & 7.00 & 128.67 & 49.505 & 47.036 & 9.921 & 48.071 & 11.906 \\
\hline & $\mathrm{E}$ & 1.2 & 6.51 & 119.60 & 49.253 & 45.648 & 8.787 & 46.486 & 10.891 \\
\hline \multirow[t]{5}{*}{ Blue GLL } & A & - & 5.35 & 100 & 41.243 & -1.584 & -23.681 & 23.734 & 266.139 \\
\hline & $\mathrm{B}$ & 1.43 & 6.50 & 121.38 & 41.871 & -2.859 & -23.844 & 24.015 & 263.129 \\
\hline & $\mathrm{C}$ & 0.78 & 6.38 & 119.10 & 41.606 & -2.274 & -23.738 & 23.847 & 264.494 \\
\hline & $\mathrm{D}$ & 0.62 & 5.29 & 98.79 & 41.452 & -2.156 & -23.529 & 23.628 & 264.73 \\
\hline & $\mathrm{E}$ & 1.33 & 6.14 & 114.67 & 41.868 & -2.032 & -24.772 & 24.855 & 265.276 \\
\hline \multirow[t]{5}{*}{ Yellow 5GLL } & $\mathrm{A}$ & - & 7.04 & 100 & 79.484 & 1.974 & 69.327 & 69.355 & 88.333 \\
\hline & $\mathrm{B}$ & 2.67 & 9.00 & 127.73 & 78.317 & 1.14 & 67.074 & 67.084 & 88.99 \\
\hline & $\mathrm{C}$ & 3.61 & 8.82 & 125.27 & 77.734 & 1.398 & 66.214 & 66.229 & 88.755 \\
\hline & $\mathrm{D}$ & 2.61 & 7.11 & 100.86 & 78.261 & 3.458 & 67.549 & 67.637 & 87.034 \\
\hline & $\mathrm{E}$ & 1.93 & 6.87 & 97.56 & 80.533 & 0.657 & 70.272 & 70.275 & 89.428 \\
\hline \multirow[t]{5}{*}{ Black FR } & $\mathrm{A}$ & - & 11.13 & 100 & 25.719 & -1.222 & -3.242 & 3.465 & 249.319 \\
\hline & B & 0.32 & 14.08 & 126.44 & 25.584 & -1.138 & -2.962 & 3.173 & 248.955 \\
\hline & $\mathrm{C}$ & 0.29 & 14.74 & 132.44 & 25.554 & -1.091 & -3.04 & 3.23 & 250.23 \\
\hline & $\mathrm{D}$ & 0.04 & 11.40 & 102.44 & 25.698 & -1.256 & -3.256 & 3.49 & 248.878 \\
\hline & $\mathrm{E}$ & 0.41 & 11.71 & 105.21 & 25.934 & -1.554 & -3.136 & 3.5 & 243.614 \\
\hline \multirow[t]{5}{*}{ Olive Green BL } & $\mathrm{A}$ & - & 6.00 & 100 & 56.367 & -7.205 & 30.301 & 31.146 & 103.406 \\
\hline & B & 4.81 & 8.00 & 133.34 & 54.763 & -10.358 & 27.032 & 28.949 & 110.993 \\
\hline & $\mathrm{C}$ & 3.67 & 7.69 & 128.23 & 55.069 & -9.492 & 27.739 & 29.318 & 108.919 \\
\hline & $\mathrm{D}$ & 2.59 & 5.72 & 95.31 & 54.225 & -6.397 & 31.53 & 32.172 & 101.5 \\
\hline & $\mathrm{E}$ & 1.50 & 5.52 & 92.11 & 55.62 & -6.141 & 29.537 & 30.169 & 101.776 \\
\hline \multirow[t]{5}{*}{ Turquoise Blue BRLE } & A & - & 7.22 & 100 & 56.316 & -29.568 & -28.716 & 41.217 & 224.145 \\
\hline & $\mathrm{B}$ & 3.75 & 8.04 & 111.35 & 55.412 & -30.528 & -25.196 & 39.583 & 219.518 \\
\hline & $\mathrm{C}$ & 3.23 & 8.02 & 111.06 & 55.197 & -30.158 & -25.744 & 39.652 & 220.469 \\
\hline & $\mathrm{D}$ & 1.45 & 6.26 & 86.67 & 55.368 & -29.189 & -27.676 & 40.224 & 223.458 \\
\hline & $\mathrm{E}$ & 2.33 & 6.06 & 83.96 & 55.464 & -29.778 & -26.55 & 39.895 & 221.703 \\
\hline
\end{tabular}

Where $A$ control (RFD) fabric dyeing, $B$ grey fabric dyeing, $C$ Desized fabric dyeing, $D$ Scoured fabric dyeing, $E$ one bath pre-treatment and dyeing

$L=0$ yields black and $L=100$ indicates white, $a$ negative values indicate green while positive values indicate red, $b$ negative values indicate blue and positive values indicate yellow, $C$ Chroma, positive values indicate More Saturated colour (i.e. brighter) and negative values indicate Less Saturated colour (i.e. duller), $h$ Hue angle or purity of colour

Colour strength measurement of dyed samples

Conventional dyeing is carried out on RFD fabric and thus for all comparisons the relative strength of the RFD fabric was taken as $100 \%$. From Table 2, it is evident that the grey fabric as well as desized fabric in all cases (dyes) showed higher relative strength and $K / S$ in comparison with that of the RFD fabric. This may be attributed to the fact that starch being present on the fabric as size also has affinity for the dyes as it is chemically similar to cellulose of cotton (Figs. 2, 3). Thus, dye adsorption by the cellulose as well as starch adhered on the grey fabric gives higher adsorption of dye leading to higher $K / S$ or colour strength.
In case of desized fabric, although large amount of starch was removed during desizing, residual starch on desizing treatment onto the fabric which can be understood by the fact that only a weight loss of $10.5 \%$ was observed whereas total amount of size present on the fabric was $12 \%$. This leads to higher absorption of dye on desized fabric compared to RFD fabric and thus higher colour strength.

When scoured fabric was dyed with direct dyes, approximately same relative strength as that of conventional dyed fabric was observed. Similarly for one step pretreatment and dyeing process, the relative strength was approximately same as the conventionally dyed fabric. 


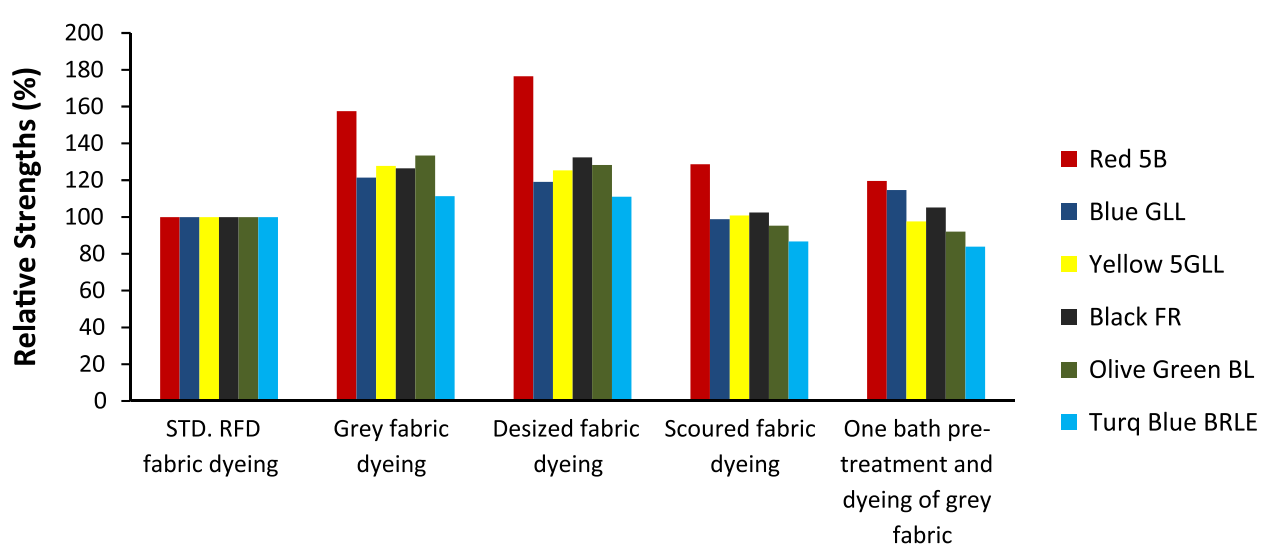

Fig. 1 Relative strengths of fabrics dyed using CB Direct dyes. Relative strengths (\%) of all the various dyed fabrics using direct dyes maintaining temperature of $100{ }^{\circ} \mathrm{C}$, for $1 \mathrm{~h}$ using material to liquor ratio (MLR) 1:20. Red column indicates Red 5B dye, dark blue

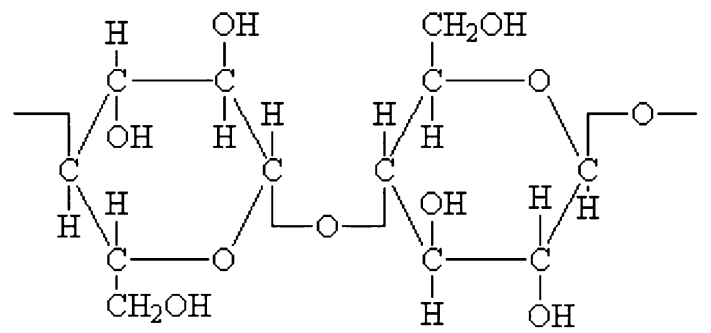

Fig. 2 Structure of cellulose. Cellulose $\left(\mathrm{C}_{6} \mathrm{H}_{10} \mathrm{O}_{5}\right)_{n}$ is a polysaccharide consisting of a linear chain of several hundred to ten thousand $\beta$-linked D-glucose units

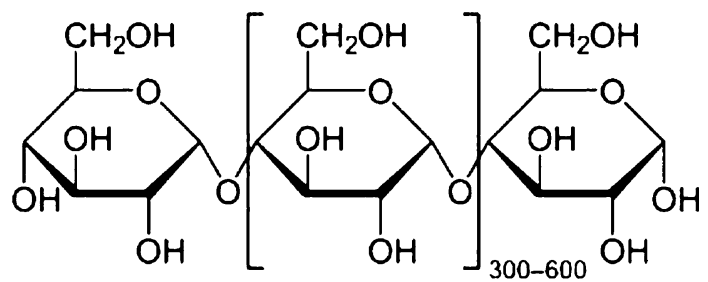

Fig. 3 Structure of starch. Starch is a carbohydrate consisting of a large number of glucose units joined by glycosidic bonds. It consists of two types of molecules: the liner (amylase) and the branched amylopectin

$\mathrm{dE}$ is a term used to denote the tonal variation between two dyed fabrics and it is observed that a $\mathrm{dE} \leq 1$ shows a tonal variation which cannot be identified by naked eye. From Table 2, it is clear that $\mathrm{dE}$ for most samples has been observed to be $<1$ which means that there is no significant tonal variation. However, for fabrics dyed with CB Direct Olive Green BL, CB Direct Yellow 5GLL and CB Direct Turquoise Blue BRLE $150 \%$, a high dE has been observed which may be attributed to the fact that unbleached fabric (grey fabric) has natural coloured impurities which are leading to the tonal variation. column indicates blue GLL dye, yellow column indicates yellow 5GLL dye, black column indicates black FR dye, green column indicates olive green $\mathrm{BL}$ dye and light blue column indicates Turquoise (Turq.) Blue BRLE dye

Table 2 also shows $L, a, b, C$ and $h$ values. Colour is judged from its lightness or darkness and its tone. The lightness or darkness is represented by the symbol $\mathrm{L}$ and the tone is specified by two components ' $a$ ' and ' $b$ '. It can be thus interpreted from Table 2 that the $L$ values of all the dyed fabrics are nearly similar to the control fabric. The only exception is with the lighter dye yellow 5GLL, where the $L$ value of grey-dyed fabric is slightly less than the control. This may be due to the fact that the grey fabric is duller in appearance than the bleached fabric (control). Chroma $(C)$ values of all the dyed fabrics were also approximately in line with the control fabric.

Higher relative strength of grey dyed fabric is attributed to presence of starch as size on the fabric leading to higher absorption as explained earlier. This can also hinder the penetration of the dye inside the core fibre. Therefore, it was thought appropriate to check the penetration of dyes into the interior of fibre. For this, cross-sectional views of the dyed fabric samples were taken under optical microscope with a magnification of $50 \times$. From Fig. 4 , it can be seen that, in all the dyed samples, the dye has penetrated into the fibre similar to the control (RFD) fabric. Figure 5 shows a cross-sectional image of a denim fabric, which is ring dyed. This cross-section was taken to confirm the fact that the dyeing carried out gives well penetrated dyeing and not ring dyeing.

\section{Colour fastness properties of dyed samples}

The fastness properties of the dyed samples were also evaluated and depicted in Table 3. All the colour fastness properties of dyed samples, i.e. washing fastness, light fastness as well as rubbing fastness were found to be at par with the control (RFD) fabric. 
Fig. 4 Cross-sectional views of yarn from direct dyed cotton fabric. Cross-sectional images of dyed yarns from control (RFD) fabric, grey dyed fabric, desized-dyed fabric, scoureddyed fabric and one bath dyed fabric were viewed under optical microscope with a magnification of $\times 50$. For this figure, fabrics dyed with $\mathrm{CB}$ Direct Blue GLL dye are chosen. Where, a indicates Control (RFD) fabric dyeing, $\mathbf{b}$ indicated Grey fabric dyeing, c indicates Desized fabric dyeing, d indicates Scoured fabric dyeing and $\mathbf{e}$ indicates One bath pre-treatment and dyeing of grey fabric
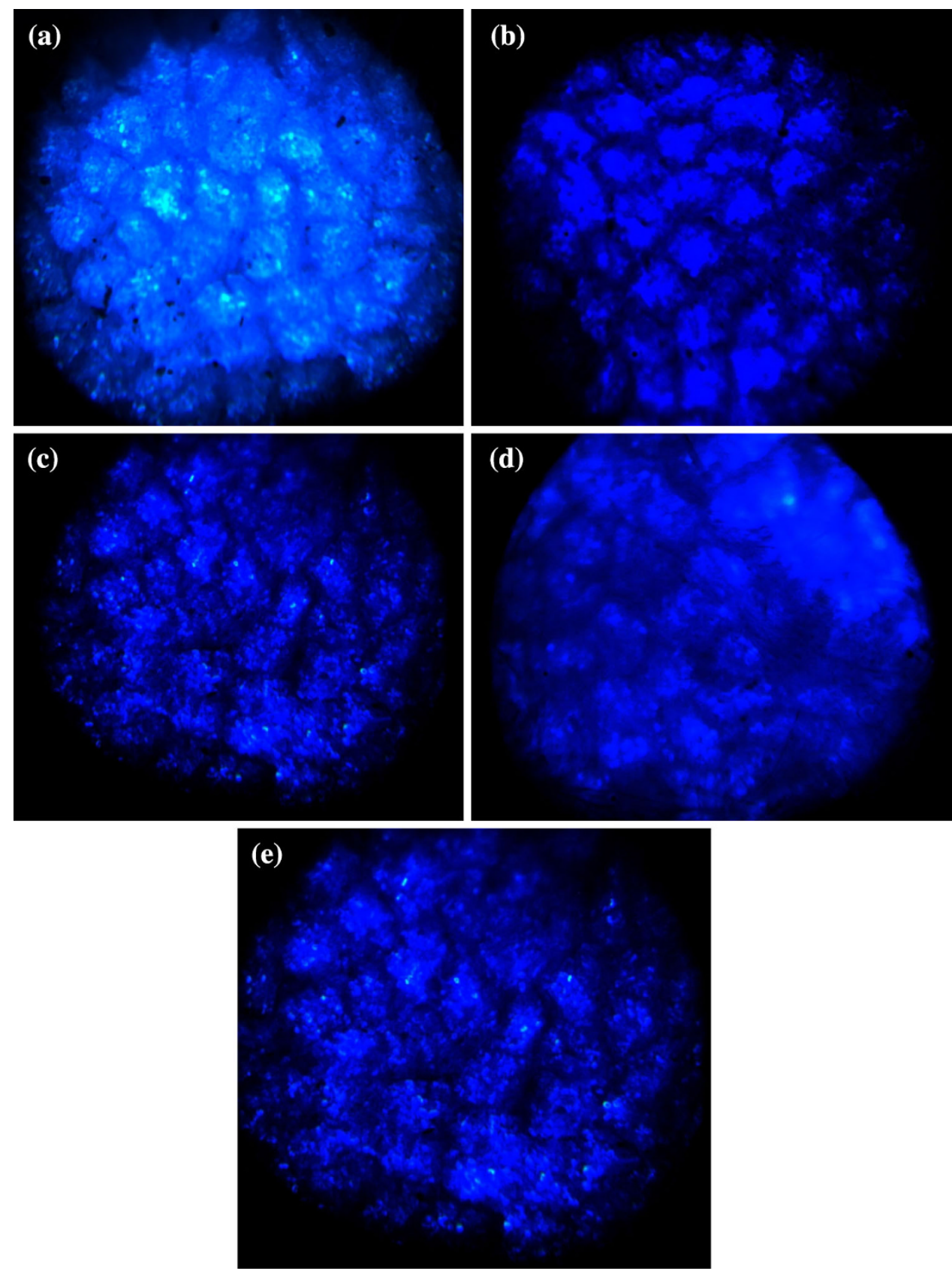

Absorbency of dyed fabric samples

The absorbency of the dyed fabrics was checked which can be seen in Table 4. Due to treatment at boiling temperature during one bath dyeing process, there is improvement in the absorbency as compared to the grey undyed fabric; however, it is lesser than the control fabric. Absorbency of dyed scoured fabric is similar to the control fabric as almost all the impurities are removed up to the scouring stage and only coloured components are left out to be removed further in bleaching.
Comparison of conventional and combined process

It is imperative to study the comparison of new process as against the well set conventional processes. Tables 5 and 6 shows the consumption of water, energy and time in conventional processes and combined process, respectively.

For calculation purpose, the fabric weight was taken as $1 \mathrm{~kg}$. The total amount of water used in the conventional processes (including the washing steps) is $529 \mathrm{~L}$ while that required by the combined process is $89 \mathrm{~L}$ (as seen from Tables 5,6). There is thus an incredible saving in the water usage which is $83.17 \%$. 


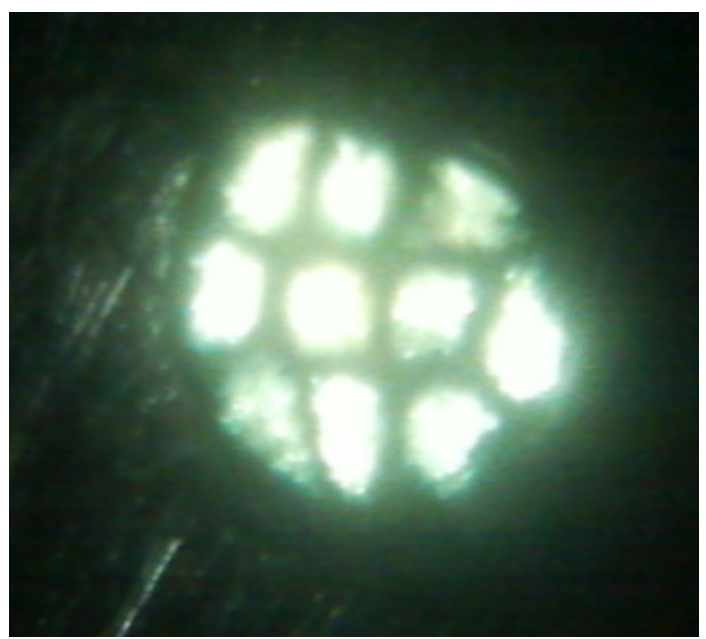

Fig. 5 A cross-sectional image of a yarn from denim fabric. Few yarns form a denim fabric were removed and viewed under an optical microscope with a magnification of $\times 50$. Ring dyeing can be seen through the cross-sectional image

The heat energy calculations were done using the following formula,

Heat required $=m(\mathrm{~kg}) \times C_{\mathrm{p}}\left(\frac{\mathrm{J}}{\mathrm{kg}^{\circ} \mathrm{C}}\right) \times \Delta T\left({ }^{\circ} \mathrm{C}\right)$

where $m=$ mass of water (Density of water $=$ $\left.1,000 \mathrm{~kg} / \mathrm{m}^{3}\right), C_{\mathrm{p}}=$ Specific heat of water $\left(4.186 \mathrm{~J} / \mathrm{kg}{ }^{\circ} \mathrm{C}\right)$

The total heat energy required for the separate pretreatment and dyeing processes is $16,930 \mathrm{kcal}$ (70801.26 kJ); for the calculation purpose, the energy loss to atmosphere was excluded. On the other hand, the energy required for the combined pre-treatment and dyeing process is $1,930 \mathrm{kcal}(8071.26 \mathrm{~kJ})$. From this, it can be seen that there is $88.60 \%$ energy saving in the combined process.

The total time required to process a grey fabric into a dyed one is $460 \mathrm{~min}$, excluding the time required for heating and cooling of the baths. This includes all the steps of pre-treatment, i.e. desizing, scouring, bleaching and then dyeing using direct dyes. On the other hand, a combined pre-treatment and dyeing process takes only $95 \mathrm{~min}$, i.e. $79.3 \%$ reduction in time for the same work.

\section{Conclusion}

The single-bath pre-treatment and dyeing method saves not only the time of treatment but also water and energy. The relative strength of these dyed samples showed good results and they were very similar or in some cases slightly higher than the control sample. The nominal reduction in the relative strength observed in few cases is due to the
Table 3 Fastness properties of fabrics dyed with direct dyes

\begin{tabular}{|c|c|c|c|c|c|c|c|}
\hline \multirow[t]{3}{*}{ Dyes/samples } & \multicolumn{7}{|c|}{ Fastness properties } \\
\hline & \multicolumn{4}{|c|}{ Washing } & \multirow[t]{2}{*}{ Light } & \multicolumn{2}{|c|}{ Rubbing } \\
\hline & & $\mathrm{CC}$ & $\mathrm{SC}$ & SW & & Dry & We \\
\hline \multirow[t]{5}{*}{ Red 5B } & A & 4 & $1-2$ & 3 & 2 & $4-5$ & 4 \\
\hline & B & $3-4$ & $1-2$ & 2 & 2 & $4-5$ & 4 \\
\hline & $\mathrm{C}$ & $3-4$ & $1-2$ & 2 & 2 & $4-5$ & 4 \\
\hline & $\mathrm{D}$ & 4 & $1-2$ & 3 & 2 & $4-5$ & 4 \\
\hline & E & 4 & $1-2$ & 2 & 2 & $4-5$ & 4 \\
\hline \multirow[t]{5}{*}{ Blue GLL } & A & $4-5$ & $3-4$ & 3 & 4 & $4-5$ & 4 \\
\hline & B & $4-5$ & 3 & 3 & 3 & $4-5$ & 4 \\
\hline & $\mathrm{C}$ & $4-5$ & 3 & 3 & 4 & $4-5$ & 4 \\
\hline & $\mathrm{D}$ & $4-5$ & $3-4$ & 3 & 4 & $4-5$ & 4 \\
\hline & E & $4-5$ & $3-4$ & $3-4$ & 3 & $4-5$ & 4 \\
\hline \multirow[t]{5}{*}{ Yellow 5GLL } & A & $4-5$ & $3-4$ & 3 & 4 & $4-5$ & $4-5$ \\
\hline & B & $4-5$ & $2-3$ & 2 & 4 & $4-5$ & $4-5$ \\
\hline & $\mathrm{C}$ & $4-5$ & $2-3$ & 2 & 5 & $4-5$ & $4-5$ \\
\hline & $\mathrm{D}$ & $3-4$ & $2-3$ & 3 & 4 & $4-5$ & $4-5$ \\
\hline & $\mathrm{E}$ & 4 & $3-4$ & 3 & 5 & $4-5$ & $4-5$ \\
\hline \multirow[t]{5}{*}{ Black FR } & A & $4-5$ & 4 & $3-4$ & 3 & $4-5$ & $4-5$ \\
\hline & B & $4-5$ & $3-4$ & 3 & 2 & $4-5$ & $4-5$ \\
\hline & $\mathrm{C}$ & 4 & $3-4$ & 3 & 3 & $4-5$ & $4-5$ \\
\hline & $\mathrm{D}$ & 4 & $3-4$ & $3-4$ & 3 & $4-5$ & $4-5$ \\
\hline & $\mathrm{E}$ & 4 & 3 & $3-4$ & 3 & $4-5$ & $4-5$ \\
\hline \multirow[t]{5}{*}{ Olive green $\mathrm{BL}$} & A & 4 & 3 & 3 & 3 & $4-5$ & $4-5$ \\
\hline & B & 4 & $2-3$ & 3 & 2 & $4-5$ & $4-5$ \\
\hline & $\mathrm{C}$ & 4 & $2-3$ & 3 & 2 & $4-5$ & $4-5$ \\
\hline & D & 4 & $2-3$ & 3 & 2 & $4-5$ & $4-5$ \\
\hline & E & 4 & 3 & 3 & 3 & $4-5$ & $4-5$ \\
\hline \multirow[t]{5}{*}{ Turq. blue BRLE } & A & 4 & $3-4$ & $3-4$ & 5 & $4-5$ & 4 \\
\hline & B & 4 & 3 & $3-4$ & 5 & $4-5$ & 4 \\
\hline & $\mathrm{C}$ & 4 & 3 & $3-4$ & 5 & $4-5$ & 4 \\
\hline & D & 4 & $3-4$ & $3-4$ & 5 & $4-5$ & 4 \\
\hline & E & 4 & 3 & 4 & 5 & $4-5$ & 4 \\
\hline
\end{tabular}

Where $A$ control (RFD) fabric dyeing, $B$ grey fabric dyeing, $C$ desized fabric dyeing, $D$ scoured fabric dyeing, $E$ one bath pre-treatment and dyeing

$C C$ change in colour, $S C$ staining on cotton, $S W$ staining on wool

Table 4 Absorbency of dyed fabrics

\begin{tabular}{ll}
\hline Samples & Absorbency (s) \\
\hline Undyed RFD fabric & $<3$ \\
Dyed control (RFD) sample & $<3$ \\
Undyed grey fabric & $>600$ \\
Dyed grey fabric & $15-20$ \\
Dyed desized fabric & $10-15$ \\
Dyed scoured fabric & $<3$ \\
One bath pre-treatment and dyed fabric & $10-12$
\end{tabular}


Table 5 Water, energy and time consumption in conventional processes

\begin{tabular}{|c|c|c|c|}
\hline Steps in the processes & $\begin{array}{l}\text { Water } \\
\text { consumption } \\
\text { (L) }\end{array}$ & $\begin{array}{l}\text { Energy } \\
\text { consumption } \\
(\text { kcal })\end{array}$ & $\begin{array}{l}\text { Time } \\
\text { consumption } \\
(\mathrm{min})\end{array}$ \\
\hline Desizing (MLR 1:30) & 30 & 900.4 & 120 \\
\hline Cold wash (MLR 1:50) & 50 & 0.0 & 5 \\
\hline Hot wash (MLR 1:50) & 50 & $3,501.7$ & 10 \\
\hline $\begin{array}{r}\text { Neutralisation } \\
\text { (MLR 1:50) }\end{array}$ & 50 & 0.0 & 10 \\
\hline Scouring (MLR 1:30) & 30 & $2,101.0$ & 120 \\
\hline Cold wash (MLR 1:50) & 50 & 0.0 & 5 \\
\hline Hot wash (MLR 1:50) & 50 & $3,501.7$ & 10 \\
\hline Bleaching (MLR 1:30) & 30 & $1,500.7$ & 60 \\
\hline Cold wash (MLR 1:50) & 50 & 0.0 & 5 \\
\hline Hot wash (MLR 1:50) & 50 & $3,501.7$ & 10 \\
\hline $\begin{array}{r}\text { Neutralisation } \\
\text { (MLR 1:50) }\end{array}$ & 50 & 0.0 & 10 \\
\hline Dyeing (MLR 1:20) & 19 & $1,330.6$ & 60 \\
\hline $\begin{array}{l}\text { Dye fixing treatment } \\
\text { (MLR 1:20) }\end{array}$ & 20 & 600.3 & 30 \\
\hline Cold wash (MLR 1:50) & 50 & 0.0 & 5 \\
\hline Total & 529 & 16,938 & 460 \\
\hline
\end{tabular}

Table 6 Water, energy and time consumption in combined process

\begin{tabular}{llll}
\hline Steps in the processes & $\begin{array}{l}\text { Water } \\
\text { consumption } \\
\text { (L) }\end{array}$ & $\begin{array}{l}\text { Energy } \\
\text { consumption } \\
\text { (kcal) }\end{array}$ & $\begin{array}{l}\text { Time } \\
\text { consumption } \\
\text { (min) }\end{array}$ \\
\hline $\begin{array}{l}\text { Combined pre- } \\
\text { treatment and dyeing } \\
\text { (MLR 1:20) }\end{array}$ & 19 & $1,330.6$ & 60 \\
$\begin{array}{l}\text { Dye fixing treatment } \\
\text { (MLR 1:20) }\end{array}$ & 20 & 600.3 & 5 \\
$\begin{array}{l}\text { Cold wash (MLR 1:50) } \\
\text { Total }\end{array}$ & 50 & 0.0 & 30 \\
& 89 & $1,930.9$ & 95
\end{tabular}

destruction of dye molecules taking place in case of sensitive dyes due to the presence of hydrogen peroxide in the bath or the products formed during degradation of size which are of reductive nature in the bath. It can also be seen that a grey unprocessed fabric can also be dyed with acceptable properties as of the RFD fabric. The combined processes lead to substantial saving in water $(83.17 \%)$, energy $(88.60 \%)$ and time $(79.3 \%)$ along with chemicals and money.

Acknowledgments Authors wish to acknowledge the Dept. of Fibres and textile Processing Technology, ICT and Technical Education Quality Improvement Programme (TEQIP) and Fund for improvement of Science and Technology (FIST) for the Grants.
Conflict of interest The authors declare that they have no competing interests.

Authors' contributions RSH has carried out all the practical work related to this research and drafted the manuscript, NRM and PBT have helped in clearing basic concepts related to the research, and helped in reviewing and drafting the manuscript. RVA has guided throughout the research work, has critically revised the manuscript and has given final approval of the version to be published. RVA has agreed to be accountable for any queries related to this manuscript. All the authors have read and approved the final manuscript.

Open Access This article is distributed under the terms of the Creative Commons Attribution License which permits any use, distribution, and reproduction in any medium, provided the original author(s) and the source are credited.

\section{References}

1. Zahran, M.K., Rehan, M.H., El-Rafie, M.H.: Single bath full bleaching of flax using an activated sodium chlorite/hexamethylene tetramine system. J. Nat. Fibers 2, 49-67 (2005)

2. Prabaharan, M., Rao, J.V.: Combined desizing, scouring and bleaching of cotton using ozone. Indian J. Fibre Text. Res. 28, 444-449 (2003)

3. Min, R.R., Huang, K.S.: Feasibility of one-step process for desizing, scouring, bleaching and mercerising of cotton fabrics: dyeing studies of direct dyes in a finite bath. J. Soc. Dyers Color 115, 69-72 (1999)

4. Shaikh, M.A.: Water conservation in textile industry. Pakistan Text. J. 11, 48-51 (2009)

5. Karmakar, S.R.: Chemical technology in the pre-treatment processes of textiles, 1st edn. Elsevier Sciences, Amsterdam (1999)

6. Harane, R.S., Adivarekar, R.V.: Simple approach for cost effective reuse of water in pre-treatments of cotton. Int. J. Chem. Tech. Res. 5(2), 671-675 (2013)

7. Polonca, P., Tavcer, P.F.: Bioscouring and bleaching of cotton with pectinase enzyme and peracetic acid in one bath. Color. Technol. 124, 36-42 (2008)

8. Saravanan, D., Sivasaravanan, S., Sudharshan Prabhu, M., Vasanthi, N.S., Senthil Raja, K., Das, A., Ramachandran, T.: One step process for desizing and bleaching of cotton fabrics using the combination of amylase and glucose oxidase enzymes. J. Appl. Polym. Sci. 123, 2445-2450 (2012)

9. Pervin, A., Davulcu, A., Eren, H.A.: Enzymatic pre-treatment of cotton. Part 2: peroxide generation in desizing liquor and bleaching. Fibres Text. East. Eur. 73(2), 87-90 (2009)

10. Adivarekar, R.V., Darade, N.P., Harane, R.S., Khurana, N.S.: Optimization of alkali and sodium persulphate for combined desizing-scouring-bleaching (D-S-B) exhaust Process. Colourage 59(3), 35-41 (2012)

11. Quandt, C., Kuhl, B.: Operational possibilities and optimisation of enzymatic processes in textile finishing industry. Melliand Engl. 10, E198-E200 (2000)

12. Hardt, P., Lund, A., May, R.: 4-in-1 process-combined bleaching and dyeing of cellulose fibres. Melliand Text. 82, E174-E710 (2001)

13. Losonczi, A., Csiszar, E., Szakacs, G.: Bleachability and dyeing properties of biopretreated and conventionally scoured cotton fabrics. Text. Res. J. 74, 501-508 (2004)

14. Kokol, V., Golob, V.: The effect of single bath treatment on reactive dyeing and bio finishing of cotton fabric. In: Paper presented at the meeting of Textile Institute 83rd World Conference, Shanghai, China, 757-762 (2004) 
15. Öner, E., Sahinbaskan, B.Y.: A new process of combined pretreatment and dyeing: REST. J. Clean. Prod. 19, 1668-1675 (2011)

16. Chougule, M.B., Sonaje, N.P.: Novel techniques of water recycling in textile wet processing through Best Management Practices (BMP's). Int. J. Appl. Sci. Adv. Technol. 1, 29-33 (2012)

17. AATCC: Technical Manual, vol. 75. AATCC, Research Triangle Park (1995)

18. AATCC: Test Method 110: Whiteness of Textiles. AATCC, Research Triangle Park (2005)

19. Sule, AD: Computer Colour Analysis: Textile Applications, 1st edn. New Age International Publishers, New Delhi (1997)

20. International Organization for Standardization: IS0 105C03: Textiles - Testsfor Colour Fastness - Part C03: Colour Fastness to Washing. ISO, Geneva (1989)

21. International Organization for Standardization: IS0 105B02: Textiles - Testsfor Colour Fastness - Part B02: Colour Fastness to Artificial Light: Xenon ArcFading Lamp Test. ISO, Geneva (2013)

22. International Organization for Standardization: IS0 105X12: Textiles - Testsfor Colour Fastness - Part X12: Colour Fastness to Rubbing. ISO, Geneva (2001)

Rachana S. Harane is currently pursuing her $\mathrm{Ph} . \mathrm{D}$. from the Department of Fibres and Textile Processing Technology, ICT, Mumbai, and her research interest lies in water conservation in textile wet processing.
Neha R. Mehra has just finished her Ph.D. from the Department of Fibres and Textile Processing Technology, ICT, Mumbai. She is currently working as a Research Associate at IIT Delhi. Her research interest focuses on non-conventional fibres, medical textiles, finishing of textiles, colouration and nanotechnology.

Priti B. Tayade has just finished her Ph.D. from the Department of Fibres and Textile Processing Technology, ICT, Mumbai. Her research areas include natural dyes, textile dyeing and printing.

Ravindra V. Adivarekar is $\mathrm{Ph} . \mathrm{D}$. degree holder (Tech) from ICT (formerly known as UDCT) Mumbai in 1995. He is, at present, a Professor of Fibre Chemistry and Head of the department at ICT. His research interests include printing of textile, natural dyes, mass production and extraction of microbial colourants, manufacturing of enzymes for textile processing, medical textile, eco-friendly processing and detergency of textiles. 